\title{
Variations in the resting oxygen consumption of small babies
}

\author{
N. RUTTER, S. M. BROWN, AND D. HULL \\ From the Department of Child Health, Nottingham University, and Nottingham City Hospital
}

SUMMARY Over 200 measurements of the resting rate of oxygen consumption using an open-circuit method were made on 15 small babies nursed in their usual clinical setting during the first month of life. There were striking and persistent variations between babies that could not be explained by postnatal age, relationship to feed, sleep, or time of day. It was not possible from clinical examination to predict which babies had the higher or lower metabolic rates, except that babies who were lightfor-dates generally had higher values. Because of these variations the appropriate thermal temperature for small babies cannot be predicted from average values adjusted for body weight and postnatal age alone.

If a small baby is nursed in an environment which is too cold for him, he responds by increasing his rate of heat production to maintain body temperature. If this cold stress persists, it may reduce his chances of survival (Silverman et al., 1958), and result in a lower rate of growth (Glass et al., 1968). If his surroundings are too hot, he may try to lose heat by sweating, his body temperature may rise, and there is a risk of apnoeic spells (Daily et al., 1969). It is therefore current policy in many neonatal units to try to nurse small babies at a temperature at which heat production is at a minimum and at which sweating does not take place. The range of ambient temperature over which this occurs is termed thermoneutral, and estimates of this thermoneutral range have been made for babies of different birthweights and postnatal ages, and for both naked and clothed babies (Hey and Katz, 1970; Hey and O'Connell, 1970). These estimates are based on measurements of heat production and evaporative water loss from babies nursed in an experimental metabolism chamber at different ambient temperatures.

In practice however, it has proved difficult to nurse babies according to Hey's recommendations which are based on average values of resting heat production and require that babies of the same birthweight and postnatal age are nursed under the same temperatures. It is our experience that nursing staff prefer to alter the incubator air temperature according to small changes in the baby's rectal temperature, whether his skin feels warm or cold, and whether he appears to be comfortable or restless. In effect,

Received 8 December 1977 they feel that babies vary in their temperature requirements.

The object of this inquiry was to examine the individuality of a group of small babies in a newborn nursery by measuring their rates of heat production serially.

\section{Method}

Heat production was measured indirectly by determining $\mathrm{O}_{2}$ consumption using an open-circuit method, as described by Smales (1978). Warm, humid air was passed at a rate of $1.01 / \mathrm{min}$ through a soft rubber face mask secured over the baby's nose and mouth, and the $\mathrm{O}_{2}$ content of the outflow measured with a paramagnetic oxygen analyser (Servomex OA250). The rate of $\mathrm{O}_{2}$ consumption is the product of the rate of flow and the difference in $\mathrm{O}_{2}$ concentration in the inflow and outflow gas. Measurements were made more than an hour after the end of a feed so as to minimise changes in $\mathrm{O}_{2}$ consumption due to the specific dynamic action of food. The baby usually settled and went to sleep after the face mask was applied, and a measurement was then made 10 to 15 minutes later. Measurements were made over a period of 3 to 15 minutes when the record was stable. The resting $\mathrm{O}_{2}$ consumption was calculated in $\mathrm{ml} / \mathrm{min}$, corrected to standard temperature and pressure, and expressed per $\mathrm{kg}$ body weight.

Oxygen consumption was measured serially in 15 babies. The first measurement was made within 24 hours of delivery and subsequent measurements were made daily for the first few days and then less 
frequently. The period of study ranged from 13 to 31 days (mean 22) and the number of measurements made on each baby was from 8 to 15 . A total of 184 measurements was made. Informed consent of the mother was obtained.

In addition, measurements were made at intervals during a period of 24 hours on 6 of the babies to see if there was any diurnal variation in heat production. The babies were cot nursed at the time of the measurements and their $\mathrm{O}_{2}$ consumption was measured 6 or 7 times during the 24 hours, as described above.

At each measurement the room temperature was recorded. If the baby was being nursed in an incubator, the incubator air temperature was also noted. The rectal temperature was recorded at the end of each measurement using a mercury thermometer inserted approximately $3 \mathrm{~cm}$ into the baby's rectum, the standard method used by our nursing staff to measure body temperature.

Subjects. Birthweights varied from 1.15 to $2.07 \mathrm{~kg}$ (mean 1.84) and gestational age from 33 weeks to term. Three babies were preterm with a birthweight appropriate for gestational age, 4 babies were term but with a weight below the 10th centile for gestational age (light-for-dates), and 8 babies were both preterm and light-for-dates. All the babies were well from birth, although 3 developed jaundice requiring phototherapy, and one developed physical signs of a patent ductus arteriosus and early congestive cardiac failure. They were fed predominantly or wholly on a modified formula milk (Gold Cap SMA, Wyeth).

Thermal environment. Measurements were made wherever the baby happened to be. Most babies were nursed in an incubator after birth for 1 to 4 days before being transferred to a cot, although the smallest baby was in an incubator for 21 days and the two heaviest babies were cot nursed from birth.
Babies nursed in incubators were usually naked apart from a disposable nappy. Radiant heat shields were not used. Incubator air temperature was selected by the nurses at a level thought to be appropriate for the baby. No incubator setting was adjusted for the purpose of the study. Phototherapy, if used, was delivered to incubator-nursed babies only. 53 measurements were on babies in incubators. Incubator air temperature varied between 31.5 and $36 \cdot 5^{\circ} \mathrm{C}$. An analysis was made of all the incubator air temperatures to see how often they were within the thermoneutral range given in the charts (Hey, 1971) for the appropriate birthweight and postnatal age, after a correction had been made for radiant heat loss to the inner surface of the incubator walls (Hey and Mount, 1967). On 31 occasions the baby was being nursed in an ambient temperature within or very close to the lower end of the thermoneutral range. On the other 22 occasions the incubator air temperature was below the recommended range. The cot-nursed babies were clothed in a long cotton night-shirt and covered with a sheet and two layers of cellulose blanket. The temperature of the room in which they were nursed averaged $27.5^{\circ} \mathrm{C}$ (range $25 \cdot 0-29 \cdot 0^{\circ} \mathrm{C}$ ). All 131 measurements on these babies were made under conditions which were thermoneutral according to Hey's estimates.

\section{Results}

The mean resting $\mathrm{O}_{2}$ consumption of all the babies measured serially is shown in Fig. 1. As it was impossible to take readings at corresponding times in each baby, the results are expressed so that each point on the graph represents the mean of all readings made within a given span of postnatal age. The resting $\mathrm{O}_{2}$ consumption rose from $5.5 \pm 0.6$ $\mathrm{ml} \mathrm{O} \mathrm{kg}^{-1} \mathrm{~min}^{-1}$ (mean $\pm \mathrm{SD}$ ) in the first 24 hours to $8 \cdot 3 \pm 1 \cdot 3 \mathrm{ml} \mathrm{O} \mathrm{kg}^{-1} \mathrm{~min}^{-1}$ (mean $\pm \mathrm{SD}$ ) from the beginning of the 2 nd week. There was some variation in each baby but, more strikingly, considerable

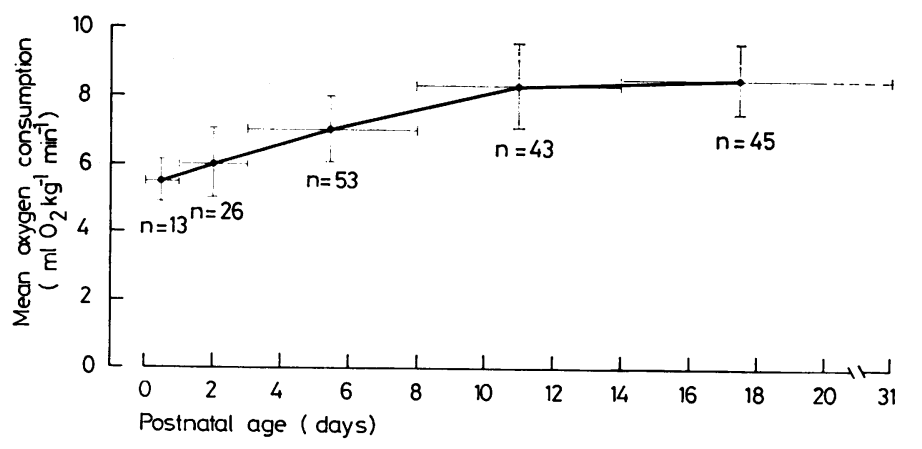

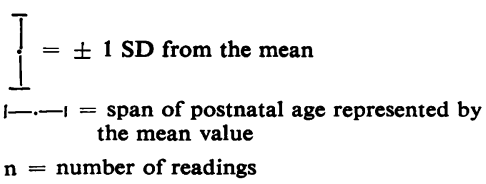

Fig. 1 Mean oxygen consumption of all 15 babies according to postnatal age. 


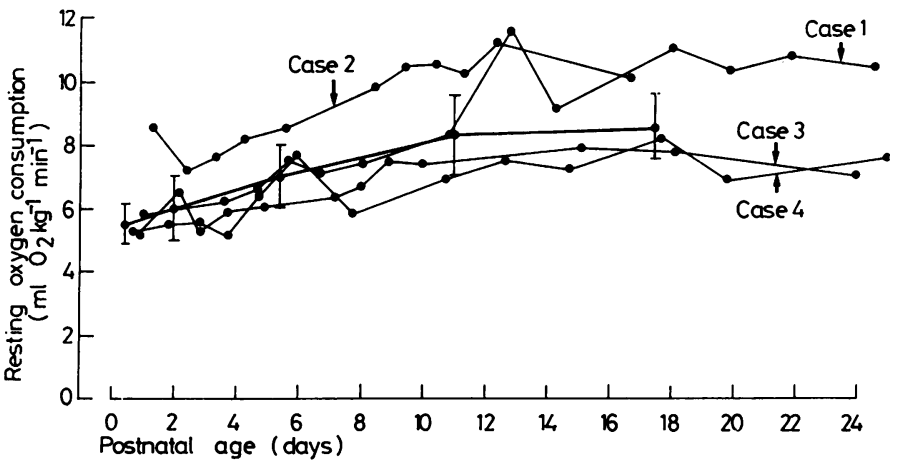

Fig. 2 Serial resting $\mathrm{O}_{2}$ consumption of 4 babies, 2 with the highest and 2 with the lowest values. Mean values of all the babies (Fig. 1) are also included.

Case 1, male twin, birthweight $1 \cdot 15$

$\mathrm{kg}$, gestation 34 weeks; developed physical signs of patent ductus arteriosus at 12 days.

Case 2, male singleton, birthweight $1.87 \mathrm{~kg}$, gestation 38 weeks. Case 3, female singleton, birthweight $1.76 \mathrm{~kg}$, gestation 34 weeks. Case 4, female singleton, birthweight $2.00 \mathrm{~kg}$, gestation 34 weeks.

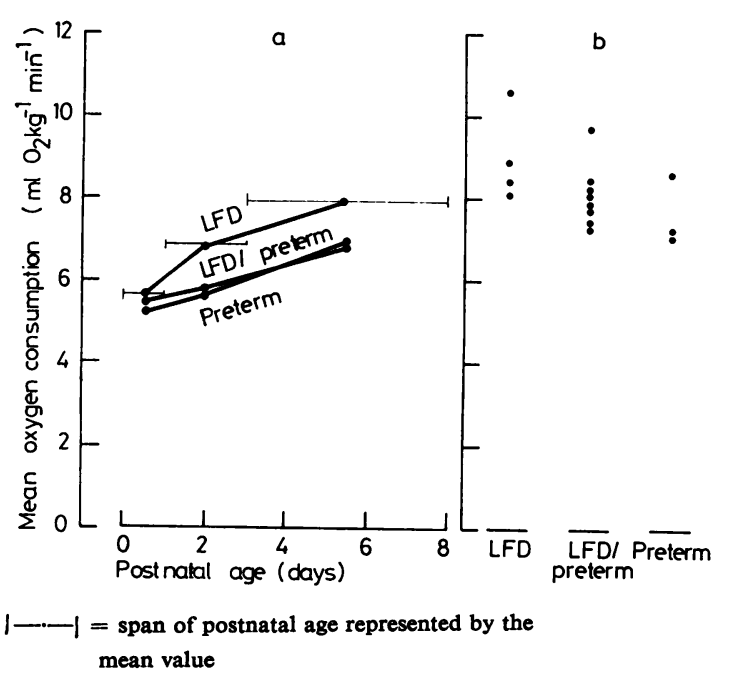

Fig. 3 (a) Mean $\mathrm{O}_{2}$ consumption in the first week according to class of baby. 4 babies were light-for-dates. (LFD); 8 babies were light-for-dates and preterm (LFD/preterm), and 3 babies were preterm only. (b) Mean of all $\mathrm{O}_{2}$ consumption measurements made after the first week in each baby according to class. variation between babies (Fig. 2). The resting $\mathrm{O}_{2}$ consumption of the baby with the highest metabolic rate was approximately $50 \%$ greater than that of the baby with the lowest metabolic rate. Fig. 3 shows the mean resting $\mathrm{O}_{2}$ consumption in the 3 different classes of baby. Those babies who were purely light-for-dates showed an earlier and greater rise in the first week (Fig. 3a), but the classes overlapped (Fig. 3b).

No correlation was found between resting $\mathrm{O}_{2}$ consumption and rectal temperature. The diurnal pattern of resting $\mathrm{O}_{2}$ consumption is shown in Fig. 4 . There was no diurnal variation, the babies with the higher values remaining high and those with the lower values remaining low throughout the 24 hours.

\section{Discussion}

Our mean values for resting rates of $\mathrm{O}_{2}$ consumption at birth and their rise in the postnatal period are similar to those found by others (Hill and Robinson, 1968; Bhakoo and Scopes, 1974), and in particular very like the results obtained by Hey (1969) using a closed-circuit metabolism chamber under conditions of strict thermoneutrality. In each baby there was

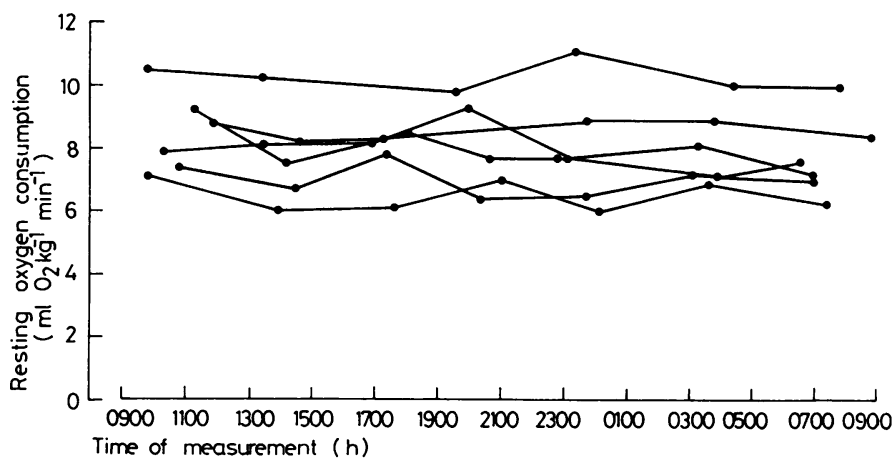

Fig. 4 Serial measurements of resting $\mathrm{O}_{2}$ consumption in 6 babies over $a$ 24-hour period. 
some fluctuation in the rate of $\mathrm{O}_{2}$ consumption over 24 hours and from day to day. This variation might be technical or it might be due to changes in response to feeding or sleep state. Stothers and Warner (1977) found $\mathrm{O}_{2}$ consumption to be only slightly increased during rapid eye movement sleep. We tried to avoid the effect of feeding on $\mathrm{O}_{2}$ consumption by only studying infants between 1 and 3 hours after a feed.

However, these changes were small compared with the differences between individual babies, as is well shown in those 6 babies who were repeatedly measured during a 24-hour period (Fig. 4). To some extent, this difference in metabolic rate could be predicted according to the class of the baby. The more rapid rise after birth in the metabolic rate of babies who are light-for-dates is well known, and even after the first week, light-for-dates babies in our study tended to have a higher resting $\mathrm{O}_{2}$ consumption per kg body weight than babies who were preterm alone. However, there was considerable overlap between the different classes of baby (Fig. 3). One of the 2 babies with the highest resting $\mathrm{O}_{2}$ consumption (Case 1, Fig. 2) was unremarkable for the first 11 days, but her $\mathrm{O}_{2}$ consumption then rose to more than $10 \mathrm{ml} / \mathrm{kg}^{-1} \mathrm{~min}$. At about this time she developed the physical signs of a patent ductis arteriosus with early congestive cardiac failure. A left-to-right shunt is known to increase metabolic rate (Kennaird, 1976). In conclusion, we found that a baby's metabolic rate could not be predicted by his birthweight and postnatal age, nor did we find any correlation between metabolic rate and rectal temperature.
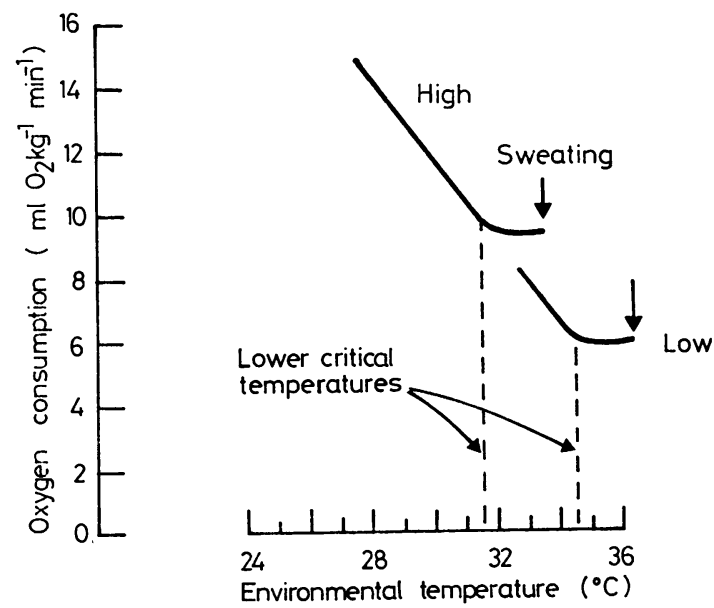

Fig. 5 Diagrammatic representation of relationship between a baby's rate of $\mathrm{O}_{2}$ consumption and the environmental temperature. As the resting metabolic rate increases, the lower critical temperature falls.
The implications of this study are illustrated in Fig. 5. When an infant has a high resting rate of $\mathrm{O}_{2}$ consumption the critical ambient temperature below which the infant must increase his metabolic rate to support his body temperature is low, but the ambient temperature at which he is at risk of hyperpyrexia is also low. In contrast, when the infant's resting metabolic rate is low, then the ambient temperature at which extra heat production is required is relatively high, as is the ambient temperature at which he is at risk of hyperpyrexia.

The infants in this study thrived and gave no problem. Most were probably nursed in the thermoneutral range as defined in the introduction, but of this we cannot be certain. If it is an advantage to keep infants at critical times after birth in thermoneutral conditions and at the same time avoid the hazards of relatively high ambient temperatures, then some index of their metabolic rates or their responses to the thermal temperature needs to be sought, for the thermoneutral environment cannot be predicted for each infant on the bases of body weight, postnatal age, and rectal temperature alone.

We thank Dr J. S. Fitzsimmons, Dr E. J. Hiller, and Dr A. D. Milner for allowing study of babies under their care, and the nursing staff of the Department of Neonatal Medicine and Surgery, Nottingham City Hospital for co-operation.

\section{References}

Bhakoo, O. N., and Scopes, J. W. (1974). Minimal rates of oxygen consumption in small-for-dates babies during the first week of life. Archives of Disease in Childhood, 49, 583-584.

Daily, W. J. R., Klaus, M., and Meyer, H. B. P. (1969). Apnea in premature infants: monitoring, incidence heart rate changes, and an effect of environmental temperature. Pediatrics, 43, 510-518.

Glass, L., Silverman, W. A., and Sinclair, J. C. (1968). Effect of the thermal environment on cold resistance and growth of small infants after the first week of life. Pediatrics, 41, 1033-1046.

Hey, E. N. (1969). The relation between environmental temperature and oxygen consumption in the new-born baby. Journal of Physiology, 200, 589-603.

Hey, E. N. (1971). The care of babies in incubators. In Recent Advances in Paediatrics, fourth edition, p. 171. Edited by D. Gairdner and D. Hull. Churchill: London.

Hey, E. N., and Katz, G. (1970). The optimum thermal environment for naked babies. Archives of Disease in Childhood, 45, 328-334.

Hey, E. N., and Mount, L. E. (1967). Heat losses from babies in incubators. Archives of Disease in Childhood, 42, 75-84.

Hey, E. N., and O'Connell, B. (1970). Oxygen consumption and heat balance in the cot-nursed baby. Archives of Disease in Childhood, 45, 335-343. 
Hill, J. R., and Robinson, D. C. (1968). Oxygen consumption in normally grown, small-for-dates, and large-for-dates new-born infants. Journal of Physiology, 199, 685-703.

Kennaird, D. L. (1976). Oxygen consumption and evaporative water loss in infants with congenital heart disease. Archives of Disease in Childhood, 51, 34-41.

Silverman, W. A., Fertig, J. W., and Berger, A. P. (1958). The influence of the thermal environment upon the survival of newly-born premature infants. Pediatrics, 22, 876-886.

Smales, O. R. C. (1978). A simple method for measuring the rate of oxygen consumption in the nursery. Archives of Disease in Childhood, 53, 53-57.

Stothers, J. K., and Warner, R. M. (1977). Oxygen consumption and sleep state in the new-born (abstract). Journal of Physiology, 269, 57P-58P.

Correspondence to Dr N. Rutter, Department of Child Health, University Hospital and Medical School, Clifton Boulevard, Nottingham NG7 2UH. 